\title{
Nodular fasciitis induced by epidural injection
}

\author{
C.C. Wray and A.W. Macdonald ${ }^{1}$ \\ Leicester Royal Infirmary and 'Leicester General Hospital, Leicester, UK.
}

\begin{abstract}
Summary: Nodular fasciitis is a well established clinical entity of unknown pathogenesis. A traumatic aetiology is postulated yet specific examples are not documented. We present a case directly attributable to an epidural injection.
\end{abstract}

\section{Introduction}

The importance of nodular fasciitis lies in its seemingly alarming malignant appearance. The synonym pseudosarcomatous fasciitis has been described as being eminently suitable as it tends to emphasize the important features in that it simulates the appearance of a sarcoma whilst also displaying inflammatory stigmata (Stout, 1961).

Since its description as a distinct clinical entity by Konwaler et al. (1955) many others have confirmed the validity of such classification (Kay, 1960; Price et al., 1961; Culberson \& Enterline, 1960). The benign nature of the lesion has been stressed (Hutter et al., 1962) and it has been suggested that recurrence following excision of a specimen originally diagnosed as nodular fasciitis should lead to careful reappraisal of the histological diagnosis (Bernstein \& Lattes, 1982).

Debate continues, however, as to the pathogenesis of nodular fasciitis. Most authors believe it to be a reactive process rather than a true neoplasm but there is little documented relationship with trauma or disease processes. Kleinstiver \& Rodriguez (1968) found no positive connection with trauma and although an association is postulated, no specific, unequivocal instances of injury in relation to nodular fasciitis have been recorded.

A case is presented where nodular fasciitis developed at the exact site of an epidural injection performed 3 years previously.

\section{Case report}

A 42 year old woman presented in the orthopaedic outpatients with a firm swelling overlying the lumbar

Correspondence: C.C. Wray F.R.C.S., Dept. of Orthopaedics, Leicester Royal Infirmary, Leicester LE1 5WW, UK.

Accepted: 26 March 1986 spine directly in the midline (Figure 1). She had noted the lesion one year previously and described it initially as being pea sized. Over that 12 months it had increased in size but was not painful or tender. She volunteered the information that an epidural injection for obstetric analgesia had been performed at exactly the same site 3 years previously.

Examination revealed a firm almost bony $3 \mathrm{~cm}$ diameter swelling overlying the L2-3 spinous process. It appeared fixed to the underlying tissues whilst the overlying skin moved freely. Plain X-rays were normal. In view of the history of injection at the same site a provisional diagnosis was made of implantation dermoid. Her obstetric notes later confirmed that an

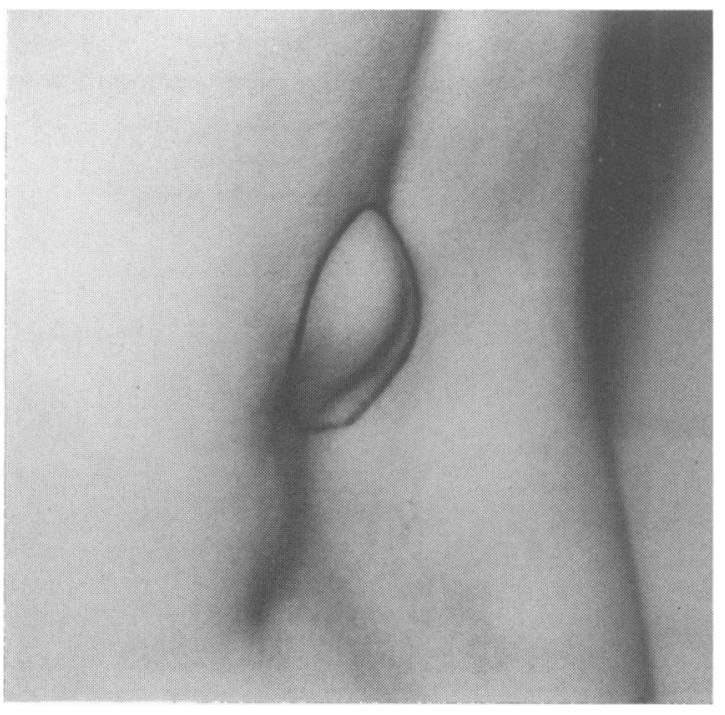

Figure 1 The firm subcutaneous swelling overlying the lumbar spine.

(C) The Fellowship of Postgraduate Medicine, 1986 
epidural anaesthetic had been administered through the $\mathrm{L} 2-\mathrm{L} 3$ interspace.

At excision biopsy, the lump was found to be arising from the deep fascia between the L2-L3 spines. It appeared well encapsulated and was dissected free without difficulty. Wound healing and the subsequent clinical progress were uneventful and at 3 month follow-up there was no evidence of recurrence. Macroscopic examination revealed a mass containing a firm pale nodule $2.5 \mathrm{~cm}$ in diameter. Microscopically the lesion was composed of spindle shaped fibroblasts showing both a random and storiform arrangement (Figure 2). The degree of cellularity varied from the more central myxoid areas with increasing cellularity towards the periphery where bundles of hyaline collagen were also present. Occasional mitotic figures were noted but none appeared bizarre. Small capillary blood vessels and extravasated red blood cells were evident especially at the advancing margin (Figure 3). Although there was no evidence of a capsule there was a distinct transition between the lesion and the surrounding connective tissue. Excision appeared complete. The appearances were those of nodular fasciitis.

\section{Discussion}

The clinical features of nodular fasciitis have been well described. There is usually a freely moveable subcutaneous mass which is not fixed to the skin. The lesions are often discovered accidentally and present most commonly during the fourth decade, although cases have been described from the age of one month to 79 years (Kleinstiver \& Rodriguez, 1968; Stout, 1961). The arms are mostly affected $(44 \%)$, followed by the leg $(25 \%)$ whilst lesions are less commonly seen

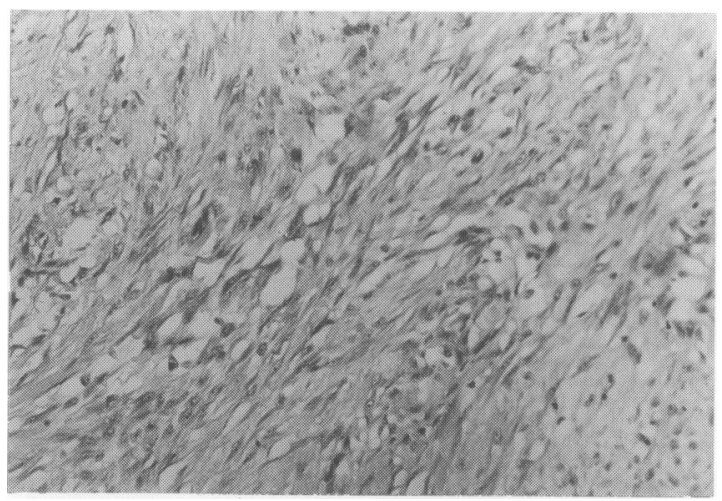

Figure 2 Typical appearance of nodular fasciitis with 'active looking' fibroblasts amidst a varying cellular picture. $\times 300$.

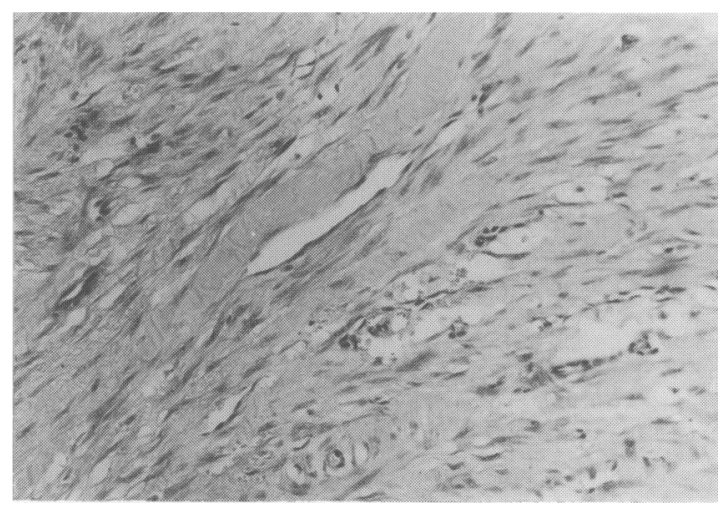

Figure 3 Hyalinised collagen bundles and small blood vessels with extravasated lymphocytes and erythrocytes. $\times 300$.

on the back (4\%) (Shimizu et al., 1984). Multiple lesions in the same patient have been recorded. The nodules are usually described as growing rapidly but as their presence when noted prompts rapid surgical attention there is no knowing how long the lesion was present before being noticed by the patient. Hutter $e t$ al. (1962) report growth was slow in $31 \%$ whilst $29 \%$ did not change in size. One of his patients had multiple nodules and the majority regressed over a 4 year period. Less is known about their pathogenesis. Part of the problem is that there is no widely accepted classification of benign fibrous tissue tumours and there is still uncertainty as to the nature of certain fibroblastic growths.

Nodular fasciitis is recognizable as an entity because of the composite of spindle-shaped fibroblasts often separated by slit-like spaces, extravasated erythrocytes, and a mucoid interstitial ground substance (Allen, 1972). Wirman (1976) has shown that the characteristic spindle cells are myofibroblasts. Such cells were originally described in experimentally-induced granulation tissue (Gabbiani et al., 1971). They have also been seen in hypertrophic scars (Baur et al., 1975) and Dupytren's contracture (Gabbiani \& Majno, 1972).

That nodular fasciitis is a reactive or inflammatory process is the current opinion adopted by most authors. Konwaler et al. (1955) in their original paper surmised that the nodules are not neoplastic and that they probably represent a sclerosing angiomatous response to an irritant. The fact that they never recur following excision would support this, and instances are recorded where residual nodules have disappeared following incomplete removal (Hutter et al., 1962). Bernstein \& Lattes (1982) point out that, histologically, nodular fasciitis resembles reparative tissue and that the nodules might represent atypical granulation 
tissue perhaps brought about by minor trauma. They also postulate that the reparative sequence of events may be initiated by other pathological mechanisms. Soule (1962) noted the similarities to a surgical scar.

Despite this consensus of opinion, there is remarkably little clinical evidence to relate nodular fasciitis to trauma. Bernstein \& Lattes (1982) document that 4\% of their patients gave a history of trauma to the area whilst Price et al. (1961) gave a figure of $11 \%$. No details of the nature of the trauma are given. Soule (1962) reports a woman who lacerated her foot and 20 days later a chain of nodules could be palpated extending up the leg. A case has been reported where nodular fasciitis appears to have developed under a splint used to protect a split skin graft (Kikuchi \& Kuroki, 1983) and more recently a case has been recorded where nodular fasciitis developed in the

\section{References}

ALlEN, P.W. (1972). Nodular fasciitis. Pathology, 4, 9.

BAUR, P.S., LARSON, D.L. \& STACEY, T.R. (1975). The observation of myofibroblasts in hypertrophic scars. Surgery, Gynecology and Obstetrics, 141, 22.

BERNSTEIN, K.E. \& LATTES, R. (1982). Nodular (pseudosarcomatous) fasciitis, a nonrecurrent lesion. Cancer, 49, 1668.

CULBERSON, J.D. \& ENTERLINE, H.T. (1960). Pseudosarcomatous fasciitis: a distinctive clinical-pathologic entity. Annals of Surgery, 151, 235.

DOHLER, J.R. \& HELBIG, B. (1985). Fasciitis nodularis beim Sportschutzen. Zeitschrift für Orthopädie und ihre Grenzgebeite, 123, 76.

GABBIANI, G., RYAN, G.B. \& MAJNO, G. (1971). Presence of modified fibroblasts in granulation tissue and their possible role in wound contraction. Experientia, 27, 549.

GABBIANI, G.B.\& MAJNO, G. (1972). Dupytren's contracture - fibroblast contraction. An ultrastructural study. American Journal of Pathology, 66, 131.

HUTTER, R.V.P., STEWART, F.W. \& FOOTE, F.W. (1962). Fasciitis. Cancer, 15, 992. upper arm of a keen marksman in the area where the rifle butt rested (Dohler \& Helbig, 1985).

We therefore present our case as a specific instance of nodular fasciitis developing after well documented surgical trauma, namely an epidural injection. This provides further evidence for the current opinion that nodular fasciitis is a reactive proliferative process rather than a true neoplasm. The development of such a nodule must also be added to the already exhaustive list of complications following epidural injection.

\section{Acknowledgements}

We thank Mr R.A. Richardson for permission to report this case.

KAY, S. (1960). Subcutaneous pseudosarcomatous fibromatosis. American Journal of Clinical Pathology, 33, 433.

KIKUCHI, I. \& KUROKI, Y. (1983). Nodular fasciitis under a splint. Journal of Dermatology, 10, 89.

KLEINSTIVER, B.J. \& RODRIGUEZ, H.A. (1968). Nodular fasciitis. Journal of Bone and Joint Surgery, 50A, 1204.

KONWALER, B.E., KEASBY, L. \& KAPLAN, L. (1955). Subcutaneous pseudosarcomatous fibromatosis (fasciitis). American Journal of Clinical Pathology, 25, 241.

PRICE, E.B., SILlIPHANT, W.M. \& SHUMAN, R. (1961). Nodular fasciitis: a clinicopathologic analysis of 65 cases. American Journal of Clinical Pathology, 35, 122.

SHIMIZU, S., HASHIMOTO, H. \& ENJOJI, M. (1984). Nodular fasciitis: an analysis of 250 patients. Pathology, 16, 161.

SOULE, E.H. (1962). Proliferative (nodular) fasciitis. Archives of Pathology, 73, 437.

STOUT, A.P. (1961). Pseudosarcomatous fasciitis in children. Cancer, 14, 1216.

WIRMAN, J.A. (1976). Nodular fasciitis; a lesion of myofibroblasts. Cancer, 38, 2378. 